\title{
Stability of antimicrobial activity of peracetic acid solutions used in the final disinfection process
}

Solange Alves da Silva COSTA ${ }^{(a)}$ Olívia Ferreira Pereira de PAULA ${ }^{(b)}$ Célia Regina Gonçalves e SILVA ${ }^{(c)}$ Mariella Vieira Pereira LEÃO(c) Silvana Soléo Ferreira dos SANTOS(c)

(a) Universidade de Taubaté - UNITAU, Department of Dentistry, Taubaté, SP, Brazil.

(b) Universidade de Taubaté - UNITAU, Department of Biology, Taubaté, SP, Brazil.

(c) Universidade de Taubaté - UNITAU, Basic Bioscience Institute, Taubaté, SP, Brazil.

Declaration of Interests: The authors certify that they have no commercial or associative interest that represents a conflict of interest in connection with the manuscript.

Corresponding Author:

Silvana Soléo Ferreira dos Santos

E-mail:silvana.soleo@uol.com.br

DOI: 10.1590/1807-3107BOR-2015.vol29.0038

Submitted: May 29, 2014

Accepted for publication: Nov 14, 2014

Last revision: Jan 15, 2015

\begin{abstract}
The instruments and materials used in health establishments are frequently exposed to microorganism contamination, and chemical products are used before sterilization to reduce occupational infection. We evaluated the antimicrobial effectiveness, physical stability, and corrosiveness of two commercial formulations of peracetic acid on experimentally contaminated specimens. Stainless steel specimens were contaminated with Staphylococcus aureus, Escherichia coli, Candida albicans, blood, and saliva and then immersed in a ready peracetic acid solution: $2 \%$ Sekusept Aktiv (SA) or 0.25\% Proxitane Alpha (PA), for different times. Then, washes of these instruments were plated in culture medium and colony-forming units counted. This procedure was repeated six times per day over 24 non-consecutive days. The corrosion capacity was assessed with the mass loss test, and the concentration of peracetic acid and $\mathrm{pH}$ of the solutions were measured with indicator tapes. Both SA and PA significantly eliminated microorganisms; however, the SA solution was stable for only 4 days, whereas PA remained stable throughout the experiment. The concentration of peracetic acid in the SA solutions decreased over time until the chemical was undetectable, although the $\mathrm{pH}$ remained at 5 . The PA solution had a concentration of $500-400 \mathrm{mg} / \mathrm{L}$ and a $\mathrm{pH}$ of 2-3. Neither formulation induced corrosion and both reduced the number of microorganisms $(p=0.0001)$. However, the differences observed in the performance of each product highlight the necessity of establishing a protocol for optimizing the use of each one.
\end{abstract}

Keywords: Peracetic Acid; Exposure to Biological Agents; Cross Infection; Disinfection; Corrosion.

\section{Introduction}

The instruments and materials used in health establishments are frequently exposed to contamination with microorganisms. Sterilization of these instruments prevents cross-infection, and the appropriate procedure before sterilization can reduce soils and organic residues and, consequently, occupational infection risk. ${ }^{1,2,3}$

Final disinfection is performed by immersing contaminated medical and dental instruments containing organic residues, microorganisms, 
and other contaminants in a disinfection solution, with the aim of eliminating or reducing the quantity of microorganisms before mechanical cleaning with soap and water. ${ }^{3}$

For many years, glutaraldehyde has been used for final disinfection. Although it is an effective disinfectant, aldehydes that remain on instruments after cleaning can promote tissue damage, especially to proteins involved in controlling cellular differentiation, thereby reducing the capacity for nucleic acid repair. ${ }^{4,5}$ Thus, glutaraldehyde use has been limited in health services, and professionals have been searching for a product with the same effectiveness but lacking the toxicity.

Peracetic acid is considered a potent biocide, even at low concentrations $(0.0001 \%$ to $0.2 \%)$. Peracetic acid has the advantages of remaining effective even in the presence of organic residues, and it decomposes into nontoxic and nonmutagenic substances (acetic acid and oxygen) and provides excellent disinfection in a short period. $6,7,8$ Parameters for the correct use of peracetic acid in disinfection procedures should thus be defined. We therefore assessed the antimicrobial effectiveness, the physical stability, and corrosiveness of two different commercial formulations of peracetic acid in a simulated final disinfection process using stainless steel specimens.

\section{Methodology}

This project was approved by the local Research Ethics Committee (CEP/UNITAU n $\left.{ }^{\circ} 038 / 11\right)$.

\section{Microorganism suspensions}

Staphylococcus aureus (ATCC 25923) was plated in mannitol salt agar (Oxoid, Hampshire, UK) and Escherichia coli (ATCC 25922) in MacConkey agar (Oxoid) for $24 \mathrm{~h}$ at $37^{\circ} \mathrm{C}$. Growing colonies were transferred to sterilized saline solution $(0.9 \% \mathrm{NaCl})$ until a suspension compatible with the $0.5 \mathrm{McF}$ arland scale standard (approximately $1.5 \times 10^{8}$ cells $/ \mathrm{mL}$ ) was obtained. Candida albicans (ATCC 18804) was plated in Sabouraud Agar (Difco, Detroit, USA) for $24 \mathrm{~h}$ at $37^{\circ} \mathrm{C}$, and the suspension was adjusted to $10^{6}$ cells/mL after counting in a Newbauer chamber.

\section{Saliva and blood samples}

On each day of the experiment, $5 \mathrm{~mL}$ saliva from the same person was collected in sterile disposable collectors (J Prolab, São José do Pinhais, Brazil). Also, blood samples were obtained from the same blood bag (Compoflex CPDA-1, Fresenius Kabi, Itapecerica da Serra, Brazil) collected from a blood donor by a local hospital. The blood bag would have been disposed of because of the presence of anti-erythrocyte antibodies. These saliva and blood samples were used to simulate the presence of organic materials that could interfere with the antimicrobial activity of the tested solutions.

\section{Experimental simulation of contamination of the specimens}

Stainless steel specimens ( $5 \mathrm{~cm}$ long, $2 \mathrm{~mm}$ diameter) were scratched and the corners were rounded with a sander (DPU 10, Panambra Industrial e Técnica S/A, São Paulo, Brazil). In a 150-mL sterile beaker, $4 \mathrm{~mL}$ of each microbial suspension, $2 \mathrm{~mL}$ saliva, and $0.4 \mathrm{~mL}$ blood were mixed. Fourteen specimens that had been previously sterilized were immersed in this contaminant suspension for $30 \mathrm{~min}$.

\section{Control specimens}

After contamination, two specimens were transferred aseptically to tubes containing $8 \mathrm{~mL}$ sterile water with peracetic acid neutralizing solution (sodium thiosulfate, $\mathrm{Na}_{2} \mathrm{~S}_{2} \mathrm{O}_{3}$, VETEC, $2 \mathrm{~g} / \mathrm{L}$, Kunigk and Almeida ${ }^{6}$ ) and glass beads. The solution was mixed for 1 min using a Vortex (Vortex-Phoenix, Araraquara, Brazil). Next, $100 \mu \mathrm{L}$ was plated in BHI medium (Difco) for total microorganism counts. The solution was also plated in mannitol salt Agar, MacConkey Agar, and Sabouraud Agar (Oxoid) with $0.1 \mathrm{mg} / \mathrm{mL}$ chloramphenicol (Quemicetina Succinato/Carlo Erba ${ }^{\circledR}$, Milano, Italy) to confirm the amounts of $S$. aureus, E. coli, and C. albicans, respectively.

\section{Disinfection procedures}

After contamination, the other 12 specimens were transferred aseptically to peracetic acid solutions: six were transferred to a ready commercial liquid solution of $0.25 \%$ peracetic acid (Proxitane Alpha $^{\circledR}$ (PA) Thech Desinfecção Ltda., São Paulo, 
Brazil; composition: peracetic acid $0.25 \%$, hydrogen peroxide $5 \%$, acetic acid $4 \%$, and stabilizing vehicle q.s.p. $100 \%$ ), and the other six were transferred to $100 \mathrm{~mL}$ of a $2 \%$ peracetic acid solution prepared with Sekusept Aktiv ${ }^{\circledR}$ powder (SA; Henkel-Ecolab, Dusseldorf, Germany; composition: > 30\% oxygenbased bleaching agents, $<5 \%$ nonionic surfactants, $30 \%-50 \%$ sodium perborate monohydrate, $15 \%-20 \%$ citric acid, $<5 \%$ fatty alcohol ethoxylate, activator for sodium perborate (TAED), complexing agent, corrosion inhibitor, fragrances) and sterile water. The manufacturer's recommendations about the use-life of these products were not clear or specific. The solutions were stored in 250-mL closed plastic containers (Plasvale, São Paulo, Brazil).

Two specimens were immersed for $10 \mathrm{~min}$ (the minimum according to the manufacturer's instructions), two for $15 \mathrm{~min}$, and two for $30 \mathrm{~min}$. The specimens were then removed and processed in the same way as the control specimens. Following vortex agitation, $100 \mu \mathrm{L}$ suspension was plated on $\mathrm{BHI}$ agar in duplicate. All plates were incubated for $48 \mathrm{~h}$ at $37^{\circ} \mathrm{C}$, and the colony-forming units (CFU) were then counted.

All procedures were repeated six times per day, four times per week, over 24 non-consecutive days (15 days of experiment) with the same disinfectant solutions.

\section{Physical analysis}

The peracetic acid concentration and $\mathrm{pH}$ were measured with indicator tape (Merckoquant 100-500, Merck \& Macherey-Nagel, Düren, Germany, respectively) at the beginning and end of each day's experiment. Storage, initial, and final room temperatures were determined each day of the experiment using an analog environmental thermometer scale with a range of -30 to $+50{ }^{\circ} \mathrm{C}$ (Incoterm, Porto Alegre, Brazil).

\section{Corrosion analysis}

The potential corrosiveness of peracetic acid solutions was verified using the mass loss test. Each specimen was weighed before and after peracetic acid exposure for $96 \mathrm{~h}$ at $60^{\circ} \mathrm{C}$ in a closed receptacle to simulate a high stress environment.

\section{Statistical analysis}

Room temperature variation was analyzed using analysis of variance followed by the Student's t test. The Mann-Whitney test was used to analyze the effects of peracetic acid by comparing the $\log \mathrm{CFU} / \mathrm{mL}$ of the control to the average $\log \mathrm{CFU} / \mathrm{mL}$ after exposure to the product for every day of the experiment and to the $\log \mathrm{CFU} / \mathrm{mL}$, regardless of exposure time, between the different experimental days. The Kruskal-Wallis test was used to compare each exposure time between the different experimental days. A level of $5 \%$ was considered significant.

\section{Results}

The total CFU/mL counts of the microorganisms from the control group and after exposure to peracetic acid solutions on each day are shown in Table 1. A significant reduction in microorganisms $(p=0.0001)$ was observed in both experimental groups compared with the control group up to day 11. After that, the SA solution was no longer tested because the solution no longer inhibited microorganism growth. The PA group retained significant microorganism-reducing potential until the last day of the experiment.

No significant change was observed in the inhibition of microorganism growth from day 1 to 4 with theSA solution. However, a significant decrease in inhibition occurred from day 4 to $8(p=0.0164)$ and from day 8 to $9(p=0.0015)$. No significant difference was observed in terms of time of exposure to SA for 10,15 , or $30 \min (p=0.5008$; data not shown).

Although an increase in microbial growth was observed throughout the experiment with the PA solution, the rate of inhibition of microorganism growth was not significant $(p>0.05)$. Similar to SA, no significant difference was observed with PA in terms of time of exposure for 10,15 , or $30 \mathrm{~min}(p=0.9498$; data not shown).

Throughout the experimental period, the storage temperature of the peracetic acid, Sekusept Aktiv ${ }^{\circledR}$ or Proxitane Alpha ${ }^{\circledR}$, ranged between 23 and $27{ }^{\circ} \mathrm{C}\left(25.7 \pm 1.4^{\circ} \mathrm{C}\right)$. The initial room temperature varied between 24 and $31{ }^{\circ} \mathrm{C}\left(27.1 \pm 2.2^{\circ} \mathrm{C}\right)$, and the final temperature was between 25 and $31{ }^{\circ} \mathrm{C}\left(27.7 \pm 1.6^{\circ} \mathrm{C}\right)$. The maximum temperature for each day ranged 
Table 1. Counts of colony-forming units per milliliter of microorganisms obtained from the control group (without disinfectant), Sekusept Aktiv $^{\circledR}$ peracetic acid (SA), and Proxitane Alfa ${ }^{\circledR}$ peracetic acid (PA) for each day of the experiment. Colony-forming units per milliliter are expressed as the logarithm.

\begin{tabular}{lccc}
\hline Day of the experiment & Control & SA & PA \\
\hline 1 & 4.51 & 0 & 0 \\
2 & 4.32 & 0.18 & 0 \\
3 & 4.75 & 0.15 & 0 \\
4 & 4.83 & 0.34 & 0.2 \\
8 & 4.17 & 0.94 & 0.16 \\
9 & 4.68 & 2.01 & 0.04 \\
10 & 4.14 & 2.12 & 0 \\
11 & 4.15 & 2.41 & 0.22 \\
15 & 4.2 & - & 0.17 \\
16 & 4.28 & - & 0.23 \\
17 & 3.75 & - & 0.14 \\
18 & 4.49 & - & 0.04 \\
22 & 3.93 & - & 0.72 \\
23 & 4.25 & - & 0.52 \\
24 & 3.87 & - & 0.33 \\
Mean & 4.29 & 1.02 & 0.18 \\
Median & 4.25 & 0.64 & 0.16 \\
Standard deviation & 0.32 & 1.01 & 0.21 \\
\hline Mann-Whitney, $p=0.0001$ (control vs. experimental groups)
\end{tabular}

between 26 and $33^{\circ} \mathrm{C}\left(29.1 \pm 2.1^{\circ} \mathrm{C}\right)$. A significant variation in temperature $(p=0.0230)$ occurred during the trial period.

The concentration of peracetic acid in the SA solution ranged from $250 \mathrm{mg} / \mathrm{L}$ to undetectable during the experimental period. These values were $250 \mathrm{mg} / \mathrm{L}$ on day $1,200 \mathrm{mg} / \mathrm{L}$ on day $2,100 \mathrm{mg} / \mathrm{L}$ on day 3 , between 100 and 0 on day 4 , and undetectable at later times. The peracetic acid in the PA solution was $500 \mathrm{mg} / \mathrm{L}$ on day 1 and $400 \mathrm{mg} / \mathrm{L}$ from days 2 to 24 . The SA solution had a $\mathrm{pH}$ of 5.0 throughout the experimental period, whereas PA had a $\mathrm{pH}$ of 2.0 on day 1 of the experiment, 2.5 from days 2 to 18 , and 3.0 at later times.

Both solutions showed no corrosion capacity because the weight of the specimens was the same before and after peracetic acid exposure.

\section{Discussion}

The effectiveness of low concentrations and short incubation times with peracetic acid in the process of sterilization and disinfection has been demonstrated. ${ }^{9,10}$ However, little is known about the stability of the antimicrobial action of this product when in contact with instruments contaminated with microorganisms and organic material such as blood and saliva. These contaminated instruments must undergo a final disinfection prior to washing, which is known as "purging" in the hospital environment, to eliminate many or all pathogenic microorganisms. ${ }^{11}$

Sudhaus et al. ${ }^{12}$ reported the influence of temperature on the microbicidal action of peracetic acid. The authors observed that higher temperatures result in lower antimicrobial action. The results of the present study showed that, during the experimental period of 24 days, although significant variations in room temperature occurred (23 to $33{ }^{\circ} \mathrm{C}, p=0.0230$ ), both peracetic acid solutions retained disinfectant potential for at least 4 days. This temperature variation occurred because of normal daily oscillations and because of the use of a Bunsen burner during the microbiological investigation procedures. We did not attempt to stabilize the temperature to more closely simulate the real situation.

While evaluating the shelf life of peracetic acid, Kunigk et al. ${ }^{13}$ showed that, at $45{ }^{\circ} \mathrm{C}$, the concentration of peracetic acid was reduced by half in $72 \mathrm{~h}$, whereas at $25^{\circ} \mathrm{C}$ the loss after 10 days was only $33 \%$. In our present work, the commercial product SA showed a $20 \%$ loss in concentration after $24 \mathrm{~h}$ and $60 \%$ after $72 \mathrm{~h}$, whereas the product PA lost $20 \%$ of the concentration only within the first $24 \mathrm{~h}$, and no further decreases were observed. In particular, the concentration of PA indicated by the manufacturer was $2,500 \mathrm{mg} / \mathrm{L}$, whereas the indicator tape used in this work detected no more than $500 \mathrm{mg} / \mathrm{L}$. If the value of $2,500 \mathrm{mg} / \mathrm{L}$ is considered as the starting concentration, an $84 \%$ loss in concentration was detected on day 2 of the experiment, and the concentration then remained stable at $400 \mathrm{mg} / \mathrm{L}$ until the end of the experimental period. Peracetic acid indicator tape in the range 100 to $500 \mathrm{mg} / \mathrm{L}$ was chosen for this experiment, because it is often accurately used to verify minimum quantities of peracetic 
acid, and this concentration range is considered sufficient for the disinfection process. ${ }^{14}$

According to Kitis ${ }^{14}$ and Zhao et al. ${ }^{15}$, a $\mathrm{pH}$ in the range of 5.5 to 10.2 results in spontaneous decomposition of peracetic acid into acetic acid and oxygen. This may have been an important factor in the difference in stability between the commercial products we evaluated, because although SA had a $\mathrm{pH}$ of 5.0, which is only 0.5 below the range of decomposition, this $\mathrm{pH}$ favors self-sustained decomposition. In contrast, PA had a pH between 2.0 and 3.0 throughout the experimental period, which is well below the peracetic acid decomposition range; this probably contributed to its greater stability.

Weak acids have potent antimicrobial activity because the non-dissociated forms pass freely through the cell membrane. When the cytoplasmic $\mathrm{pH}$ is higher than that of the growth medium, the weak acid dissociates, releasing a proton and acidifying the cytoplasm. ${ }^{16}$ Thus, a low $\mathrm{pH}$, which was lower in the PA solution than the SA solution, may also be responsible for microorganism elimination.

The results of this work demonstrated that the product SA maintained its disinfectant effectiveness until day 4 of use, whereas PA was effective until day 24 and perhaps later. Considering the microorganism growth on days 22 and 23, to guarantee a lower risk during the washing process of medical instruments, the results suggest that the PA solution can be re-used for a maximum of 18 non-consecutive days of use or 12 consecutive days for final disinfection.

Although the PA product $(0.25 \%)$ had a lower concentration of peracetic acid, the better results observed in this study may be due to differences in the composition of the products, which may have interfered with the stability. The exposure times did not significantly impact microbial reduction, suggesting that peracetic acid solutions can be used for only $10 \mathrm{~min}$, making this process faster and avoiding other problems with exposure for longer times. This shorter exposure time compared to what is necessary with glutaraldehyde $(30 \mathrm{~min})$ permits faster disinfection of biomedical instruments and materials.
Although peracetic acid has been thought to perhaps induce corrosion of biomedical instruments, our results confirmed the manufacturers' information that corrosion of stainless steel materials when using the specific conditions in this study does not occur. A temperature of $60{ }^{\circ} \mathrm{C}$ was used in the analysis because an increase in temperature reduces the resistance of these materials and increases the susceptibility to corrosion. ${ }^{17}$ The high temperature may have contributed to the decomposition of peracetic acid, influencing the real corrosion capacity of the products. Thus, tests using lower temperatures should be performed to confirm these data.

Other types of stainless steel with different qualities are sometimes used, and these may be affected differently by the disinfection process. The stainless steel used in this study was an austenitic standard grade, AISI Type $304 \mathrm{~L}$, which is considered to have high resistance to corrosion.

Healthcare professionals should be reminded that the final disinfection process (the process that aims to reduce the presence of microbes, thereby reducing the risk of contamination during instrument washing) differs from the process of disinfection, because the instruments are usually soiled (i.e., blood, saliva, or fluids in addition to microorganisms are commonly present). An instrument must be free of organic material before an effective disinfection process can begin.

Analysis of the results of this work also demonstrated an important difference in the stability of the commercial products used in the final disinfection process, suggesting that further studies should be conducted with other peracetic acid products, both by the manufacturers and by independent researchers, to establish a reliable and secure time period for the re-use of each product.

\section{Conclusion}

The peracetic acid products were stable and provided effective disinfection for at least 4 days with no corrosion capacity. However, the differences observed in the performance of each product highlight the necessity of establishing a protocol for the optimal use of each one. 


\section{References}

1. Dettenkofer M, Block C. Hospital disinfection: efficacy and safety issues. Curr Opin Infect Dis. 2005 Aug;18(4):320-5.

2. Dettenkofer M, Spencer R. Importance of environmental decontamination - a critical view. J Hosp Infect. 2007 Jun;65 Suppl 2:55-7.

3. Gilmour D. Instrument integrity and sterility: the perioperative practitioner's responsibilities. J Perioper Pract. 2008 Jul;18(7):292-6.

4. McGregor D, Bolt H, Cogliano V, Ritchter-Reichhelm HB. Formaldehyde and glutaraldehyde and nasal cytotoxicity: case study within the context of the 2006 IPCS Human Framework for the Analysis of a cancer mode of action for humans. Crit Rev Toxicol. 2006 Nov-Dec;36(10):821-35.

5. Takigawa T, Endo Y. Effects of glutaraldehyde exposure on human health. J Occup Health. 2006 Mar;48(2):75-87.

6. Kunigk L, Almeida MCB. Action of peracetic acid on Escherichia coli and Staphylococcus aureus in suspension or settled on stainless steel surfaces. Braz J Microbiol. 2001 Jan-Mar;32(1):38-41.

7. Wutzler P, Sauerbrei A. Virucidal activity of the new disinfectant monopercitric acid. Lett Appl Microbiol. 2004;39(2):194-8.

8. Bore E, Langsrud S. Characterization of micro-organisms isolated from dairy industry after cleaning and fogging disinfection with alkyl amine and peracetic acid. J Appl Microbiol. 2005;98(1):96-105.

9. Chassot ALC, Poisl MIP, Samuel SMW. In vivo and in vitro evaluation of the efficacy of a peracetic acid-based disinfectant for decontamination of acrylic resins. Braz Dent J. 2006;17(2):117-21.
10. Lorena NOS, Pitombo MB, Côrtes PB, Maya MC, Silva MG, Carvalho AC, et al. Mycobacterium massiliense BRA100 strain recovered from postsurgical infections: resistance to high concentrations of glutaraldehyde and alternative solutions for high level disinfection. Acta Cir Bras. 2010 Oct;25(5):455-9.

11. Maltezou HC, Fusco FM, Schilling S, De Iaco G, Gottschalk $\mathrm{R}$, Brodt $\mathrm{HR}$, et al. Infection control practices in facilities for highly infectious diseases across Europe. J Hosp Infect. 2012 Jul;81(3):184-91.

12. Sudhaus N, Pina-Pérez MC, Martínez A, Klein G. Inactivation kinetics of spores of Bacillus cereus strains treated by a peracetic acid-based disinfectant at different concentrations and temperatures. Foodborne Pathog Dis. 2012 May; 9(5):442-52.

13. Kunigk LDR, Gomes FF, Vidal KP, Gomes LF, Sousa $\mathrm{PF}$. The influence of temperature on the decomposition kinetics of peracetic acid in solutions. Braz J Chem Eng. 2001 Jun;18(2):217-20.

14. Kitis M. Disinfection of wastewater with peracetic acid: a review. Environ Int. 2004 Mar;30(1):47-55.

15. Zhao X, Cheng K, Hao J, Liu D. Preparation of peracetic acid from hydrogen peroxide, part II: Kinetics for spontaneous decomposition of peracetic acid in the liquid phase. J Mol Catal A Chem. 2008 Apr;284(1-2):58-68.

16. Cotter PD, Hill C. Surviving the acid test: responses of gram-positive bacteria to low $\mathrm{pH}$. Microbiol Mol Biol Rev. 2003 Sep;67(3):429-53.

17. Pakshir M, Bagheri T, Kazemi MR. In vitro evaluation of the electrochemical behaviour of stainless steel and Ni$\mathrm{Ti}$ orthodontic archwires at different temperatures. Eur J Orthod. 2013 Jul:35(4):407-13. 